\title{
Das Malojasyndrom
}

\section{Enrico Danieli}

Dr. med., Facharzt für Allgemeine Innere Medizin, Mitglied FMH

\author{
«Das Steigen hat seine Grenze, \\ aber nicht das Fallen." \\ (Friedrich Hebbel; 1813-1863; Tagebücher)
}

Die Direttissima ist der direkteste Weg, besser Route, ist Abkürzung, ist nicht der vorgegebene Pfad, sondern derjenige, der Zeitersparnis - Kitzel? - verspricht. Die Direttissima der Eigernordwand ist berühmt, eine Passage grösster Gefahr, grösster Herausforderung. Aufwärts, senkrecht, nur das Ziel, der himmelnahe Gipfel zählt. Die Direttissima ist Falllinie im rechten Winkel zu den Höhenlinien, sie setzt Selbstgewissheit, Lebenssouveränität, Mut, Todesmut voraus.

Die Oberengadiner Seenplatte, das Hochplateau, der Fluss, die Lärchenwälder, die Grandhotels, die Weltkurorte, die Viertausender, das betäubende Licht, der berauschende Wind. Flimmern und Glimmen, betäubte und verdrehte Sinne. Ein ebener Weg, gewunden, Gleichgesinnte in Vorwärtsbewegung. Einhalten, schauen, einkehren. Langsam sich dem Ziel nähern. Es war schön. Es hat sich gelohnt trotz des Aufwands von Tagen, Wochen: Müdigkeit, wunde Stellen, Schlafbedürfnis, auch eine gewisse Sattheit - es reicht! Als Abschluss wartet Maloja, Maloggia, das Dorf 1815 Meter über dem Meer, und der Pass, der nicht noch weiter in die Höhe führt, sondern als Direttissima steil abwärts. Das Familiengrab der Segantinis auf dem kleinen Campo Santo. Zu früh, viel zu früh, starb Segantini $1899 \mathrm{im}$ Alter von 41 Jahren. Erinnerungen an sein letztes, unvollendetes Triptychon-Bild La Morte: Eisesstarr wird ein totes Mädchen (zu früh, viel zu früh) im Morgenlicht auf einer Bahre aus einem Haus getragen, begleitet von Schwarzgekleideten, der Schlitten wartet auf die Abfahrt ins Bild hinein in Richtung aufgehender Sonne, eine entengleiche Wolke zwischen Gipfel und Himmel. Und die marmitte, die Gletschermühlen, die tiefsten (16 Meter) der Welt, Zeugen der letzten Eiszeit. Und oberhalb der Alp Lughin die Wasserscheide, da, wo sich das Wasser entscheidet, wohin es fliessen will, in die Donau, den Po oder den Rhein - Schwarzes Meer, Mittelmeer, Nordsee. Der Ort gilt als das Dach Europas. Und benachbart der einst der Verbindung zwischen Norden und Süden dienende Septimerpass oder der Römerweg Malögin von Maloja in die Tiefe mit für die Ewigkeit im Fels eingekerbten Radspuren

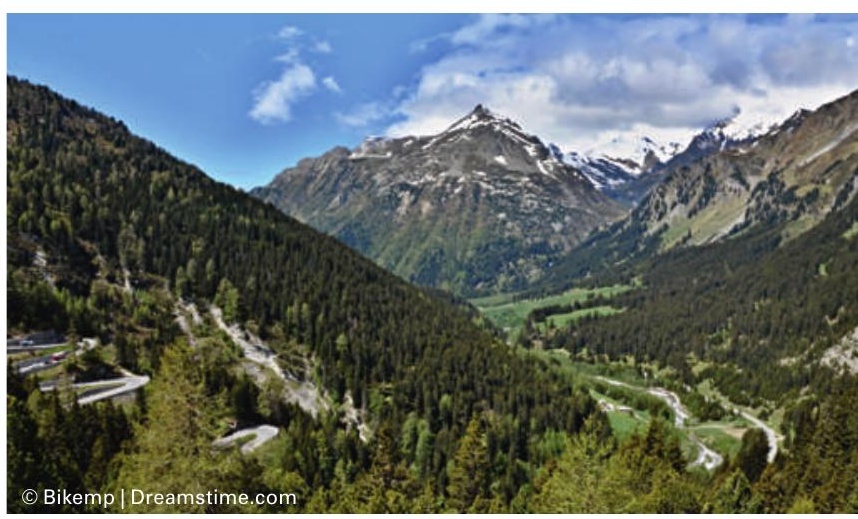

Der Malojapass ist ein 1815 Meter über dem Meeresspiegel gelegener Schweizer Alpenpass und verbindet das Bergell mit dem Engadin.

der Karren der Römer. Maloja: ein Ort, ohne Zweifel, wo die Zeitenspannen fassbar werden: Eiszeit, Römer vergängliches Heute. Vor dem Dorf am Ufer des Sees das einstige Hôtel Kursaal de la Maloja, das heutige Maloja Palace Hotel, einst das grösste, modernste Hotel Europas (Monte Carlo in Maloja), mit einem Speisesaal für 400 Gäste, einer eigenen salle de bal-concert, eigenem Golfplatz, mit Schiffsanlegestellen für Vaporetti nur zwei Monate nach der alle Grenzen sprengenden Eröffnungsfeier am 1. Juli 1884 stirbt die schöne junge Gräfin Malvina, die Ehefrau des belgischen Hotelbesitzers Comte Camille de Renesse, sie ist nur 38-jährig Mit ihrem Tod ist der Untergang der Märchenwelt, der Maloja-Magie, besiegelt. Nur eine kleine kurze Strecke trieb das Leben leidenschaftlich hier in Maloja. Der Maloja-Valse für Malvina liess die Aristokratie eine Nacht lang tanzen. Maloja befindet sich am Abgrund, über dem Abgrund. Hinter Maloja brechen die Berge jäh ab, stürzen, fallen in die Tiefe, geheissen Malojadrift. Hervorgerufen durch die jahrtausendealte rückschreitende Erosion der Gletscher. Unten, tief unten im Tal das Bergell, dort beginnt der Süden. Der Süden liegt - wie auf Karten - unten: Das Paradies liegt unten. Oder oben?

Die umgekehrte Direttissima lässt uns fallen in der Falllinie. Nicht den endlosen Kehren, Drehung um Drehung, serpentinenhaft, tal- und südwärts würden wir folgen, nicht zum Abstieg, sondern zum Absturz, Abfall oder zur Abfahrt oder zum Abflug mit unbekanntem Ziel uns entscheiden. Zuvor hätten wir abgewogen, hin und her die Argumente geschoben, doch die Tatsache der Sattheit nach dem aufwendigen Hinweg, das Wissen um die Relativierung allen zeitlichen Geschehens, das Wissen um die Einsicht in das Einst, das Damals, das Heute, das Früh, das Viel-zu-Früh hatte uns zu diesem Entschluss geführt. Das Gefühl der Vergeblichkeit hatte uns schliesslich so entscheiden lassen: Es reicht! Besser kurz und jäh als lang und mühsam, besser früher als zu spät. Hinter uns liegen die Mühen der Aufstiege, vor uns die noch grösseren Mühen der Abstiege. 